\title{
Hadrien Buclin, Maurice Blanchot ou l'autonomie littéraire
}

\section{Simonetta Valenti}

\section{(2) OpenEdition}

\section{Journals}

Édition électronique

URL : http://journals.openedition.org/studifrancesi/958

DOI : 10.4000/studifrancesi.958

ISSN : 2421-5856

Éditeur

Rosenberg \& Sellier

Édition imprimée

Date de publication : 1 août 2015

Pagination : 409

ISSN : 0039-2944

Référence électronique

Simonetta Valenti, "Hadrien Buclin, Maurice Blanchot ou l'autonomie littéraire », Studi Francesi [En ligne], 176 (LIX | II) | 2015, mis en ligne le 01 août 2015, consulté le 18 septembre 2020. URL : http:// journals.openedition.org/studifrancesi/958; DOI : https://doi.org/10.4000/studifrancesi.958

Ce document a été généré automatiquement le 18 septembre 2020.

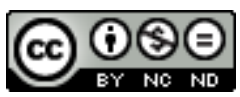

Studi Francesi è distribuita con Licenza Creative Commons Attribuzione - Non commerciale - Non opere derivate 4.0 Internazionale. 


\title{
Hadrien Buclin, Maurice Blanchot ou l'autonomie littéraire
}

\author{
Simonetta Valenti
}

\section{RÉFÉRENCE}

HADRIEN BUCLIN, Maurice Blanchot ou l'autonomie littéraire, Lausanne, Antipode, 2011, pp. 125.

1 S'étant affirmée au lendemain de la Libération, la personnalité de Maurice Blanchot s'impose à la fois en tant qu'élément de rupture par rapport à l'idéologie communiste, issue de la Résistance, et en tant que facteur d'originalité, par rapport à l'image de l'écrivain engagé, largement dominante dans le panorama culturel français de l'aprèsguerre.

Plus spécifiquement, Hadrien Buclin tente de démontrer, à travers l'étude de la biographie et de la production blanchotienne, la manière dont l'auteur de Thomas l'obscur utilise la conception de l'autonomie littéraire - puisée certes chez Mallarmé, mais aussi chez Hölderlin, Kafka et Valéry -, afin de justifier, et même d'ennoblir, sa conception d'une littérature autonome, c'est-à-dire libre de tout lien à la réalité et par là même capable de garantir la pureté de l'instance littéraire en tant que telle.

3 De l'avis de Buclin, cependant, l'autonomisation de la littérature s'accompagne chez Blanchot à une exigence bien plus pragmatique: celle de se forger une image qui puisse lui assurer un certain prestige au sein d'un champ littéraire - celui des années 1950 -, sensiblement orienté à gauche, à l'intérieur duquel l'on ne peut ignorer par ailleurs l'énorme influence de Sartre.

4 Le chapitre I («Les Milieux littéraires dans l'immédiat après-guerre en France», pp. 17-32) et le chapitre II («Maurice Blanchot au sortir de la guerre», pp. 33-50) montrent que, ayant débuté dans des revues liées à la droite nationaliste de Maurras, Drieu La Rochelle, Brasillach et Maxence, Blanchot réussit habilement à échapper au climat d'épuration intellectuelle qui s'instaure en France au lendemain de la Libération. 
Grâce à l'amitié et à l'aide de Jean Paulhan et de Georges Bataille, l'auteur parvient d'ailleurs à renouveler l'exigence d'une littérature affranchie de toute contrainte historique, pour affirmer au contraire la nature fuyante et foncièrement ambiguë de l'entreprise littéraire (cf. chapitre III, «Un Repositionnement par la critique littéraire», pp. 51-76). Autrement dit, la littérature apparait à l'auteur de La Part du feu comme le véhicule des incertitudes de l'homme contemporain, pris entre les pièges des fausses apparences et des cauchemars surgis de l'inconscient, dont le roman Le Très-Haut fournit, au dire de Buclin, le témoignage le plus probant.

Ainsi, dans l'oscillation constante entre réalité et vision onirique, vérité et mensonge, essence et apparence, oscillation qui est mise en scène constamment dans les récits de Maurice Blanchot, l'écrivain arrive à se positionner au sein du champ littéraire français, en légitimant et son retrait et la posture du prophète de l'ambiguïté qui feront sa fortune vers la fin des années 50, une fois évanoui le monopole sartrien (cf. chapitre IV, «Le Très-Haut et les récits», pp. 77-113).

6 Par l'intérêt de sa perspective critique et l'originalité de sa méthode d'analyse, empruntées essentiellement à l'étude de la société et des données culturelles, l'essai d'Hadrien Buclin parvient donc à éclaircir la position de Blanchot dans le domaine des lettres françaises et à nous faire comprendre la contribution - nourrie parfois du désir subtil de s'imposer auprès du grand public - d'un écrivain, connu comme le courageux champion de l'autonomie littéraire. 